\title{
GIS-based framework for assessing neglect in the historic built environment
}

\author{
G. Newman \& B. Kim \\ Department of Landscape Architecture and Urban Planning, \\ Texas A\&M University, College Station, USA
}

\begin{abstract}
Population and land use migrations from historic urban areas have resulted in urban environments characterized by non-functional, unmaintained structures. These structures can deteriorate to the point where rehabilitation costs outweigh renovation costs - a process known as demolition by neglect. Historic preservation policies attempt to salvage these structures primarily through local policy, on a building by building basis. The climbing rate of neglected historic structures is a growing concern which creates the need for research which seeks to identify, measure, and monitor the condition of urban areas on a larger scale; extending beyond the current unit by unit basis. This research presents a framework to identify concentrations of neglected space in historic urban core areas using Geographic Information Systems. Buildings were surveyed and geocoded in three historic boroughs in Bucks County, Pennsylvania, USA. Each structure was analyzed based on its age, condition, value, degree of modification, and land use change and scored using Newman's (in press) model of measuring neglect. The total scores were then utilized to categorize each structure in reference to its degree of neglect. Spatial analyses were then performed combining Hot Spot Analysis, Weighted Suitability, and Inverse Distance Weighted Interpolation to define proportions of the urban core areas which were in need of immediate regeneration. On average, around $1 / 4$ of each borough's historic urban core was undergoing some form of neglect, suggesting multiple adaptive reuse, retrofit, or renovation efforts are necessary to stymie future demolition of heritage resources.

Keywords: demolition by neglect, historic preservation, growth management, geographic information systems, Geodesign, urbanization, urban regeneration.
\end{abstract}




\section{Introduction}

The impact of centrifugal development on inner-city, historic structures as both vitality (people) and viability (function) have fled to the periphery has been dire, leaving many historic structures to rot as vacant, unused shells of their former selves. As cities expand across countless parcels of the American landscape, they leave in their wakes - especially in historic centers - vacant lands, derelict lands, and building stock no longer suitable for their original purposes [1]. This expansion often accelerates the removal of heritage structures that have deteriorated due to a lack of use, a process known as demolition by neglect (DBN).

Decentralized growth is spreading a homogenous form across the landscape, destroying multiple layers of cultural history [2]. Historic areas have not received the support necessary to maintain their viability, protect their structural integrity and heritage values, and stimulate their local economic base as populations and occupancies continue to undergo various incremental transformation processes. These transformations are tied largely to regional growth patterns as many peripheral lands that serve as the settings to historic structures have also become threatened. People must begin to look beyond traditional preservation ordinances and landmark commissions to address the planning forces that have the most influence over their city's future development [3]. The ability of preservation standards to support both the historic character of sites and their viability depends increasingly on effective processes for examining changes within the larger town or urban context [4], but since contexts are constantly in flux, form and function rarely coincide sustainably in any environment [5]. According to historic preservation theory, the contemporary tendency is to give priority to form by means of thorough documentation and in-depth historic interpretation. An unfortunate fallacy to this premise is that when building function dissolves, too often the building form itself is simply removed or rebuilt.

\section{Neglect and heritage management}

DBN can be defined as the destruction of a heritage landscape or area through abandonment or lack of maintenance [6]. It has become an epidemic within historic areas and a challenging issue for state and local authorities. DBN can contradict the traditional philosophy of historic preservation in America [7], the salient reason that oftentimes not enough is done to prevent this condition. Neglect begins when an owner disregards a property to the point that the property suffers damage. This process can be either intentional, when a proprietor allows decay of an historic property maliciously, or unintentional, when a property owner simply does not have the financial means to maintain an historic building. Causes can include deferred maintenance, developmental pursuits, absentee ownership, circumstantial outcomes, and function relocation [8]. Although building loss cannot always be prevented due to unstoppable and unpreventable acts of nature, removal of historic structures can be prevented more often if causes are mediated better. 
Most risk factors to historic structures are incipient and progressive, making historic structures outside of preservation programs particularly vulnerable. These risks extend to all portions of the landscape, but especially exist in areas where development pressures and urbanization have occurred. Many historic urban areas have not received the attention and support they deserve to maintain viability, protect structural integrity and heritage value, and stimulate local economic bases as populations and occupancies undergo various incremental transformations [9]. As both populations and functions continue mass exoduses from inner cities and small towns, major allotments of historic fabric are left abandoned, amplifying the process. Consequently, large concentrations of the nation's aged treasures are eradicated from the landscape.

Most American historic structures are regulated on a unit-by-unit basis - even those within historic districts — and are assessed primarily according to their ability to look as they did at a particular historic point. According to Jigyasu [9], historic structures have two fundamental dimensions: the first deals with aspects of historic integrity, but the second deals with their relationships to the living environment in which they exist. It is important to examine both the historic structure itself and its dynamic regional context to understand the process of DBN fully. Mediation of the historic built environment should consider not only monuments, but also the settings of preserved structures. Too often, historic preservation is presented simply as a matter of technocratic planning and other architectural details such as the color to use when painting structures, but it involves much wider considerations.

Neglect deteriorates a heritage structure slowly until it is deemed irreconcilable. This process is a recognized heritage planning issue globally, and as of 2007, the number of demolition applications being submitted was on the rise [8]. The term DBN gained popularity in the early to mid-1990s - a phrase coined to raise awareness of the loss of historic structures. Unfortunately, only a minimum of research was conducted on the topic, and until recently, the term became an afterthought in preservation. Although the stint in the early to mid-1990s brought demolition by neglect to the forefront of preservationist thought, research on the issue has quietly ceased while the phenomenon continues to plague the country's historic structures. The State Preservation League of New York held a conference on demolition by neglect in 1993, and the National Trust for Historic Preservation held a panel discussion and presentation on this topic at the 1994 national convention in Boston. By 1994, the United States Preservation Commission Identification Project report listed neglect as the most difficult situation for local commissions to solve, with only $25 \%$ of respondents reporting they had the authority to protect designated structures from demolition by neglect [10].

DBN can contradict the traditional philosophy of historic preservation in America. Historic preservationists attempt to counteract demolition of historic buildings by placing restrictions on individual structures that disallow removal, but this strategy can sometimes only delay a structure's inevitable demise [9]. This can occur if there is an overdependence on the value of historic integrity and architectural significance (i.e., aesthetics) in lieu of function [7], a loophole in contemporary preservation philosophy. Conflicts between the preservation of the 
character of existing historic towns and their ability to incorporate necessary change, forms the salient reason not enough is done to prevent this condition [11]. For example, preservation policy places strong value on factors long considered intangible, such as architectural merit and societal importance. Preservation philosophy demands that property owners recognize and accept this value. Value depends on interpretation, but the value preservationists place on a structure is not always the same as the value an owner may hold.

Local approaches to regulating heritage structures is more likely to attract investors into the heritage conservation market, but due to weaknesses in broader conservation regulations, the result is the potential loss of important nonrenewable heritage resources [12]. Rethinking spatial planning to enhance more proactive forms of heritage management has been an iterative process since the nascence of historic preservation. Historic preservationists continue the effort to create a more flexible discipline regarding management of the local built environment based on larger scale factors [13]. The approach of American preservationists differs from European heritage management by remaining primarily locally regulated, while European cities, especially in the United Kingdom and the Netherlands, practice an area-based approach when managing the historic built environment [14]. Similar to this area-based approach, Listokin's [15] theory posits that growth management and historic preservation are intrinsically linked but the connections between the two are not fully understood. Pickerill and Pickard [16] postulate within this connection, local authorities alone do not sufficiently meet the needs of conservation of built heritage. Case study evidence from historic areas in Germany has shown the constraints imposed by wider economic and political contexts have a significant impact on preserved structures, demonstrating the need for integrating historic preservation projects with a comprehensive urban planning framework [17]. More contemporary research has shown a disjuncture between preservation and the broader land use and building policies necessary for this integration, specifically in regards to the long term sustainability of preserved structures [18]. Historic preservation is an integral component of a larger system and must align its aims with those of this larger system if the process of neglect is to be stymied.

\section{Methodology and study area}

The rich tradition of heritage studies in North America and Europe shows a gap in application of GIS analytical methods to the historic built environment. This is unfortunate, as these landscapes, which contain unique aspects of the global cultural heritage, have been constantly modified from their indigenous state [19]. Little work has been done on the potential utilization of GIS and attribute mapping through building surveys in an effort to understand urban change historic environment. Satellite imagery to monitor urban growth [20] and the combination of this imagery with GIS to plan for growth [21] has been readily employed. The limitations to these approaches are that they rely solely on satellite images which are not thorough enough to measure neglect. This makes it difficult to conduct longitudinal studies as well. 
The utilization of GIS to examine historic urban morphology and change has not been effectively employed to progress the field of preservation, specifically in regards to monitoring neglected structures. Due to data limitations and practical concerns, most spatial analysis in the historic built environment focuses on assessing future growth and its impacts rather than the evaluation of building vitality and viability. This paper seeks to develop a technological framework for identifying areas in historic districts or towns which are in immediate need of regeneration using Geographic Information Systems (GIS). This approach seeks to advance the notion of an area-based approach for heritage management. Peter Nijkamp [22] states when evaluation measurements in conservation planning are conducted, impacts have to be measured on multiple scales which are appropriate for meaningful analysis. He posits that the cultural sector often faces situations where limited precision is presented and that ordinal, nominal, or cardinal scales can be employed to more precisely evaluate more subjective topics, especially issues such as urban degradation.

Newman's model [23] (in press) of measuring neglect was applied to statistical and spatial analysis tools using GIS. It combines existing models using historic integrity and structural viability into five explanatory variables: time frame of construction (the time frame in which the structure was erected), architectural modification (whether or not the structure has been altered since construction), land use change (the consistency of building function), physical condition (the quality of the condition or appearance of each structure), and assessed value (the fair market value). Enough buildings were surveyed within the downtown area of each borough to obtain a $95 \%$ confidence level using a clustered, non-independent random-spatial sampling method known as multistage area sampling [24] (see Fig. 1). Each variable was then divided into three measures, which were used as measures to compare neglect rates.

The historic colonial boroughs under investigation - Doylestown, Quakertown, and Bristol - are all located in Bucks County, Pennsylvania. Bucks Co. is replete with heritage landscapes, and the state of PA has adopted the practice of agricultural preservation to aid in conserving the historic distinctiveness that characterizes its townships and boroughs. Agriculture is both the leading industry and a deeply held symbol of heritage in the region [25]. These two characteristics have made Pennsylvania the nation's leader in agricultural preservation in terms of amount of monetary resources devoted to farmland preservation. Bucks County, PA is under deep suburban developmental pressures. Once a destination in its own right, the county is currently absorbing the exurban developments of both New York City and Philadelphia. Located 45 minutes north of Philadelphia and 1.5 hours from New York City, rural Bucks County is absorbing much of the exurban development of the neighboring two metropolises. The county lost $70 \%$ of its farmland between 1950 and 1997, a drop in acreage from over 260,000 to less than 84,000 [26]. The region is also ranked number two on a list of the nation's 20 most threatened agricultural lands [27]. Each borough is listed on the National Register of Historic Places [28]. 


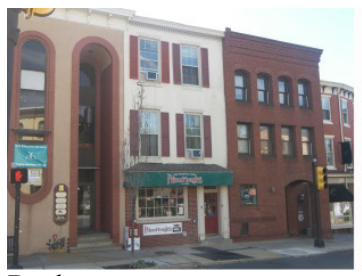

Doylestown

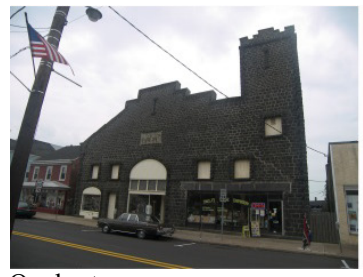

Quakertown

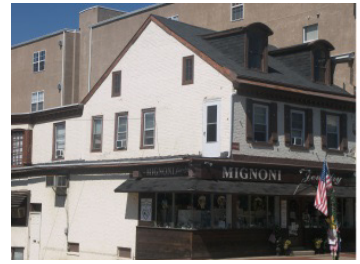

Bristol
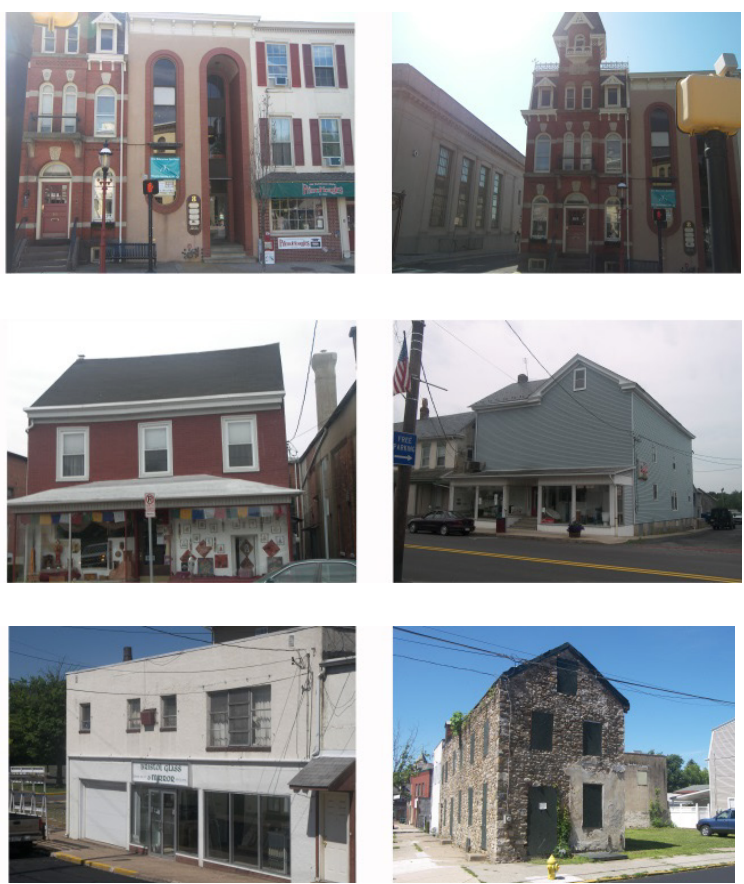

Figure 1: Selected structures sampled per town.

The research utilized two scales of analysis: a micro scale which maps and evaluated attributes of the measures used to assess each variable and a cross-case spatial analysis combining geocoding, attribute reclassification, Inverse Distance Weighted interpolation, Hot Spot, and Weighted Suitability analyses (see Fig. 2). The micro scale determined which measures impacted the variables and the cross case comparison analyzed the concentration of neglected space within each sample frame. It assessed the explanatory variables by scoring the measures on an ordinal scale $(1 \mathrm{~s}, 2 \mathrm{~s}$, and $3 \mathrm{~s})$. Each measure was placed on a gradient where a score of "1" indicated high neglect, " 2 " indicated moderate neglect, and " 3 " indicated low neglect (see Table 1). Higher scores indicated lower neglect in occurrence. The cross case comparison used overall neglect rates and hot spot analyses overlay mappings to determine neglected portions of the historic built environment and areas for potential regeneration. Hot spot analysis was then performed for each spatially located variable and then equally weighted suitability analyses were created from each hot spot analysis to create a composite mapping.

\section{Findings}

The micro scale inventoried the condition of the existing historic built environment based on three different measures for each explanatory variable 
which were scored from 1 to 3 (the higher the score, the lower the neglect). The sum score of each structure could therefore fall between 5 (all measures scoring 1) to 15 (all measures scoring 3 ).

All three towns showed similar trends in their structural inventory of the historic built environment (see Table 2). Doylestown showed the highest proportion of structures built between 1971 to present $(60 \%)$ and a large portion of structures proved to be vacant (69\%). Over $1 / 2$ of the samples structures had been adaptively reused (60\%) and a high ratio was in good condition $(86 \%)$. Quakertown showed the highest proportion of historic structures built between 1940 and 1970 (36\%) many of which were vacant (64\%) and/or dilapidated (74\%). Those that were not seemed to have an assessed value above the market mean (47\%). In Bristol, only 44\% of surveyed structures were built between 1971 to present but the town has the highest amount of vacant buildings $(80 \%)$. Nearly $1 / 3$ of them had been renovated (65\%) and another $1 / 3$ were dilapidated $(67 \%)$. However, Bristol did have the highest proportion of high valued structures $(93 \%)$.

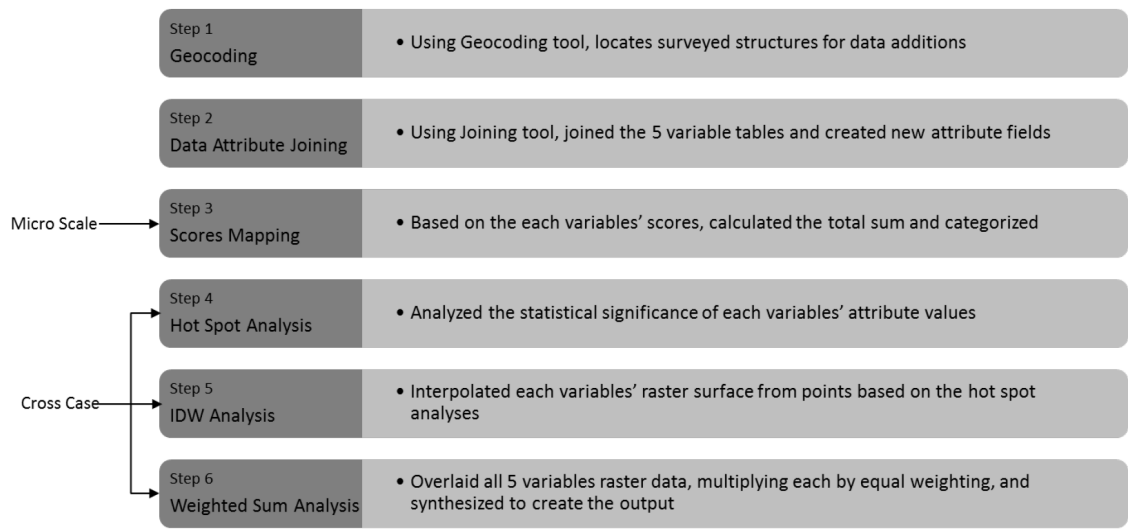

Figure 2: GIS process utilized.

Each structure sampled was given a total score (according to the nominal scale utilized) and mapped as a point value according to this score. Neglected structures were categorized as points with scores of 5-8, transitory structures had a score of 9-12, and viable structures had a score of 13-15 (see Table 3). Doylestown had the smallest ratio of neglected structures (1.5\%), followed by Quakertown $(3.1 \%)$, and then Bristol (9.1\%). However, Bristol had the largest portion of transitory structures $(81.8 \%$ ) followed by Doylestown (almost same portion with $80 \%$ ), and then Quakertown (78.5\%). Doylestown and Quakertown had similar portions of viable structures (18.5\%) with Bristol having only $9.1 \%$ viable. 
Table 1: Variables and measure scores utilized.

\begin{tabular}{|c|c|c|c|c|c|}
\hline Score & $\begin{array}{c}\text { Time frame } \\
\text { of const. }\end{array}$ & $\begin{array}{c}\text { Land use } \\
\text { change }\end{array}$ & $\begin{array}{c}\text { Architectural } \\
\text { modification }\end{array}$ & $\begin{array}{c}\text { Building } \\
\text { condition }\end{array}$ & Assessed value \\
\hline 1 & $1970-$ pres. & Vacant & Modern & Dilapidated & $\$ 0-81,000$ \\
\hline 2 & $1941-1970$ & Alternate use & Modified & Moderate & $\$ 82,000-162,000$ \\
\hline 3 & $1900-1940$ & Continuous & Authentic & Well-composed & $\$ 163,000-243,000$ \\
\hline
\end{tabular}

Table 2: $\quad$ Inventory of measures accepted of structures sampled per town.

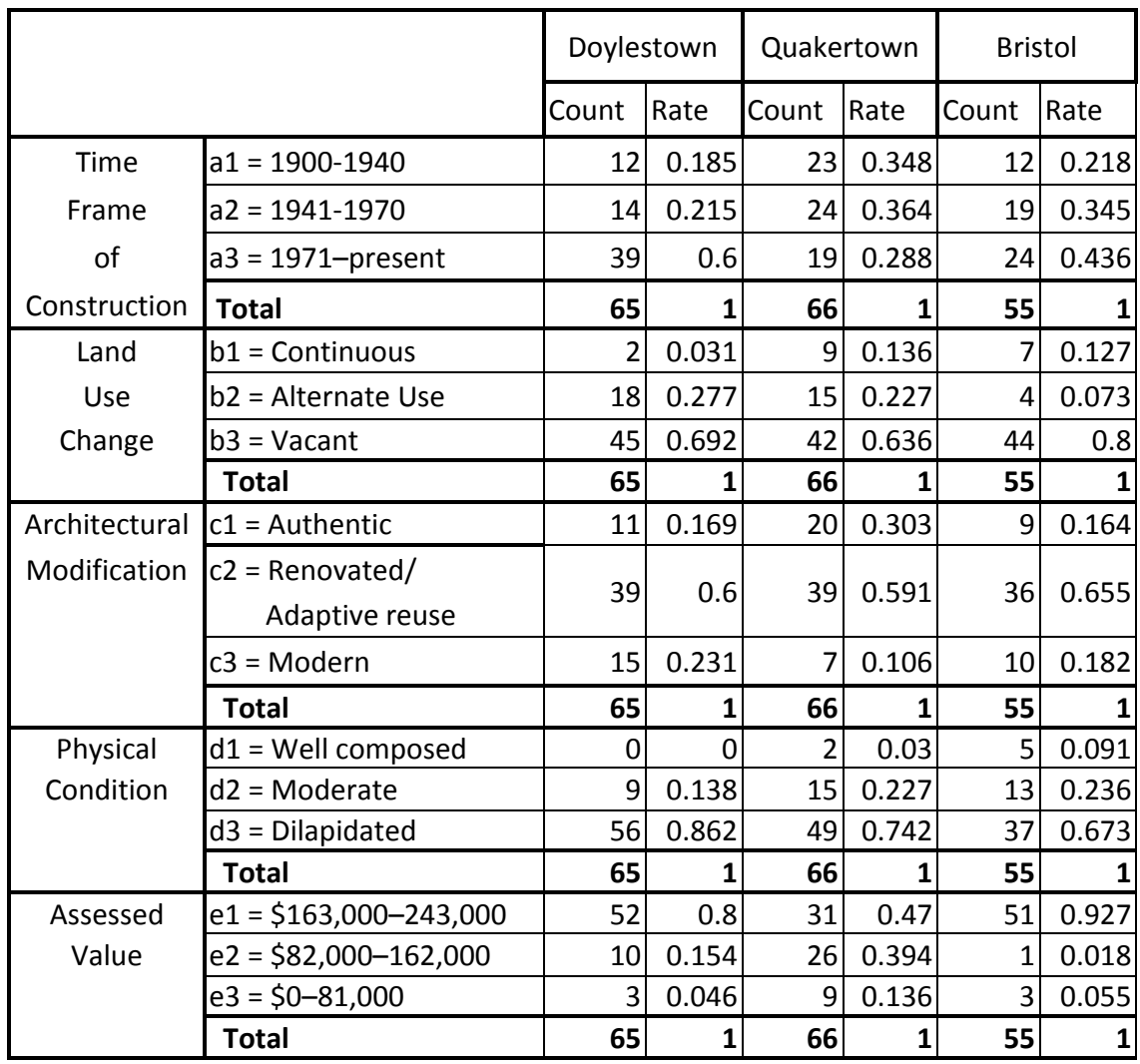

The cross case analysis was a series of spatial analysis tools, using GIS. The address of each structure was geocoded, attribute fields were added according to the building survey analysis, neglected structures were mapped, and the Hotspot analysis tool and Inverse Distance Weighted (IDW) interpolation tools were used to spatially analyze the statistical significance of each variable examined. Larger $z$-scores indicated more intense the clustering of high values. (hot $\mathrm{spot}=$ high neglect). While negative and/or smaller z-scores represented more intense clustering of low values (cold spot $=$ low neglect). The IDW interpolation tool 
represented the combination of a set of surveyed points using cell values [29]. The results were analyzed individually per town for each variable and then combined using weighted sum overlays. This concept is based on the assumption that each feature has a relationship with its neighboring features.

While the statistical significance was based on p-value and z-scores for the Hotspot analysis, to effectively visualize the results, the Inverse Distance weighted (IDW) interpolation tool was used. Based on the IDW results, the portion of the study areas within each category was calculated. The results of the overlaid five variables analyses shows the black area (represented neglecting areas) and the white area (represented the viable areas) (see Table 4). Doylestown shows almost half of the study area represented viable areas $(48.38 \%)$ while the neglected area is only $22.21 \%$. Quakertown shows $24.18 \%$ of viable area and $18.37 \%$ neglected space. Bristol shows only $2.22 \%$ viable area while $37.58 \%$ area is neglected. Corollary, the overall rate of neglected structures was 25\% for Doylestown, $30 \%$ for Quakertown, and 31\% for Bristol.

Table 3: $\quad$ Mapped scores per structure.

\begin{tabular}{|c|c|c|c|c|c|c|}
\hline & \multicolumn{2}{|c|}{ Doylestown } & \multicolumn{2}{c|}{ Quakertown } & \multicolumn{2}{c|}{ Bristol } \\
\cline { 2 - 7 } & $\mathrm{n}$ & $\%$ & $\mathrm{n}$ & $\%$ & $\mathrm{n}$ & $\%$ \\
\hline Neglected (5-8) & 1 & 1.5 & 2 & 3.1 & 5 & 9.1 \\
\hline Transitory (9-12) & 52 & 80 & 51 & 78.5 & 45 & 81.8 \\
\hline Viable (13-15) & 12 & 18.5 & 12 & 18.5 & 5 & 9.1 \\
\hline
\end{tabular}

Table 4: Percentage breakdown of the IDW.

\begin{tabular}{|c|l|c|c|c|}
\hline \multicolumn{2}{|l|}{} & Doylestown & Quakertown & Bristol \\
\hline \multirow{3}{*}{ Neglected (Black) } & $(<-2.58)$ & & & \\
\cline { 2 - 3 } & $(-2.58-1.96)$ & $22.21 \%$ & $18.37 \%$ & $37.58 \%$ \\
\cline { 2 - 3 } Grey (Transitory) & $(-1.96-1.65)$ & & & \\
\hline \multirow{2}{*}{ Viable (White) } & $(-1.65-1.65)$ & $29.41 \%$ & $57.45 \%$ & $60.20 \%$ \\
\cline { 1 - 2 } & $(1.65-1.96)$ & & & \multirow{2}{*}{$48.38 \%$} \\
\cline { 2 - 2 } & $(>2.58)$ & & $24.18 \%$ & $2.22 \%$ \\
\hline
\end{tabular}

\section{Conclusions and outlook}

Results indicate the combination of thorough inventorying, attribute mapping, and Hot Spot overlay analyses can adequately map urban conservation areas in need of regeneration. Overall, the rate of viable area in each historic borough averaged around $25 \%$ for each city, primarily due to the city's abilities to retain continuous land uses in structures and their increase in property values. The ability to retain heritage structures was high throughout all cases while these buildings also tended 
to remain in a lower state of disrepair indicated by low vacancy rates. However, these conditions appeared to be dependent on high rates of land use change. Increases in the modification of the historic structures for maintenance purposes and high amounts of modern built structures indicated a necessary sacrifice in historic integrity for the purposes of retaining viable structures.

The Hot Spot Analysis identified areas within each city in need of regeneration. On average, around $1 / 4$ of each historic borough's historic fabric was undergoing some form of neglect, suggesting multiple adaptive reuse, retrofit, or renovation efforts are necessary to stymie future demolition of heritage properties. Around $50 \%$ of the study area was in transition. This means that a majority of the spaces are in danger of succumbing to future neglect if polices are not implemented in the near future. A central argument for monitoring neglected space is that cities cannot recognize, understand, improve or maintain what they do not measure. The act of measuring alteration of the characteristics of heritage building stock involves the repeated collection of information through time and analysis of the results for detection of changes in occurrence. The collection of information will facilitate the identification of neglected space or structures which are susceptible to damage. Problematic areas, once identified, can be monitored more intensively and, where appropriate, management action taken.

New research on the subject of demolition by neglect must begin to gain a firm grasp on current public perceptions on preserved structures and rates of neglected structures within historic districts to serve as benchmarks for new data to be compared against. Too long has the ambiguity of the overall condition of historic built environments been overlooked while neglect continues to amplify. New technologies afford the opportunity to measure, monitor, and map characteristics of existing and potential historic building stock. A baseline set of data will set the stage for an increase in public value and awareness as well as serve as a foundation for longitudinal studies to compare against over time in an effort to stymie the impact of demolition by neglect within the historic built environment.

Historic preservation is intrinsically linked to urban growth. This linkage needs to be better studied and quantified. Current research has exposed a multitude of gaps within this linkage, but none have attempted to measure specific impacts of external growth management strategies on the internal historic built environment. Historic landscapes have a metabolism, and therefore need to be studied longitudinally. While there has been some movement toward integration of local historic preservation into regional growth management systems, preservation is not seen as a central issue [15]. The model presented provides a theoretical link with which to create a set of baseline data fundamental to regulating contextual change while monitoring internal impacts. Application of the model encourages much-needed cooperation between two fields that strive for similar goals. To measure impacts of regional growth on historic districts, data generated must be studied continually, and changes in the system of growth that might contribute to these impacts must be documented. Through continual feedback produced by this model, a closer, mutually beneficial, and symbiotic relationship between growth and preservation will be realized. As new growth strategies are employed and 
impacts measured, regions stressing preservation as a primary goal can use growth strategies proven to increase the vitality and viability of historic districts.

\section{References}

[1] Treib, M., Review of Drosscape: Wasting Land in Urban America, by Alan Berger. Landscape Journal, 27(1), pp. 154-155, 2008.

[2] Yahner, T.G. \& Nadenicek, D.J., Community by design: contemporary problems-historic resolve. Landscape and urban planning, 39(2), pp. 137-151, 1997.

[3] Collins, R., Waters, E.B. \& Dotson, A.B., America's Downtowns: Growth. Politics and Preservation. Washington, D.C: The Preservation Press, 1991.

[4] Alderson, C.R., Responding to context: changing perspectives on appropriate change in historic settings. APT Bulletin, 37(4), pp. 22-33, 2006.

[5] Jackson, J.B., Landscape in sight: Looking at America. Yale University Press, 1997.

[6] Moshen, M. \& Leatherborrow, D., Weathering: the Life of Buildings in Time. Cambridge, MA: M.I.T. Press, 1993.

[7] Cook, R.E., Is landscape preservation an oxymoron. The George Wright Forum, 13(1), pp. 42-53, 1996.

[8] Wallace, P., \& Franchetti, A., Heritage at Risk: Addressing the Issue of the Demolition by Neglect of Historic Heritage in New Zealand, New Zealand Historic Places Trust, Wellington Sustainable Management of Historic Heritage, Discussion paper, 6, 2007.

[9] Jigyasu, R., Monuments and Sites in Their Setting: Conserving Cultural Heritage in Changing Townscapes and Landscapes. Paper prepared for the International Centre for the Study of the Preservation and Restoration of Cultural Property (ICCROM) Symposium, India, 2002.

[10] Goldwyn, A.M., Demolition by Neglect: A Loophole in Preservation Policy. $\mathrm{PhD}$ dissertation. University of Pennsylvania, 1995.

[11] Nasser, N. Planning for urban heritage places: Reconciling conservation, tourism, and sustainable development. Journal of Planning Literature, 17 (4), pp. 467-479.

[12] Pickerill, T. \& Armitage, L., The management of built heritage: A comparative review of policies and practice in Western Europe. Dublin Institute of Technology, School of Real Estate and Construction Economics. Conference Paper - Pacific Rim Real Estate Society, 15th Annual Conference, University of Technology Sydney (UTS), North America and Australia. January 18-21, 2009.

[13] Listokin, D., Listokin, B. \& Lahr, M., The contributions of historic preservation to housing and economic development. Housing Policy Debate, pp. 431-478, 1998. 
[14] Doratli, N., Revitalizing historic urban quarters: A model for determining the most relevant strategic approach. European Planning Studies, 13(5), pp. 749-772, 2005.

[15] Listokin, D., Growth Management and Historic Preservation: Best Practices for Synthesis. The Urban Lawyer, pp. 199-213, 1997.

[16] Pickerill, T. \& Pickard, R., A review of fiscal measures to benefit heritage conservation. RICS Research Paper Series 7(6), 2007.

[17] Alberts, H.C., \& Mark R. Brinda, M.R., Changing approaches to historic preservation in Quedlinburg, Germany. Urban Affairs Review, 40(3), pp. 390-401, 2005.

[18] Avrami, E., A systems approach to historic preservation in an era of sustainability planning. PhD dissertation. Rutgers University, 2012.

[19] Stewart, D.J., New tricks with old maps: urban landscape change, GIS, and historic preservation in the less developed world. The Professional Geographer, 53(3), pp. 361-373, 2001.

[20] Mahavir, G.M., Monitoring urban growth using SPOT images and aerial photographs. ITC Journal, 2, pp. 63-69, 1991.

[21] Haack, B., Craven, D. \& McDonald Jampoler, S., GIS tracks Kathmandu Valley's urban expansion. GIS World 9, pp. 54, 1996.

[22] Nijkamp, P., Evaluation measurement in conservation planning. Journal of Cultural Economics, 15(1), pp. 1-27, 1991.

[23] Newman, G., A Conceptual Model for Measuring Demolition by Neglect. Journal of Preservation Education and Research, 6, 2014 (forthcoming).

[24] Montello, D. \& Sutton, P.C. An introduction to scientific research methods in geography. Thousand Oaks, CA: Sage Publications, 2006.

[25] Bourke, L., Jacob, S. \& Luloff, A.E., Response to Pennsylvania's Agricultural Preservation Programs. Rural sociology, 61(4), pp. 606-629, 1996.

[26] U.S. Department of Agriculture. Urban Ecosystem Analysis of the Delaware River Valley: Calculating the Value of Nature, Washington, DC: American Forests, 2005.

[27] Olson, R.K. \& Lyson, T.A., Under the blade: the conversion of agricultural landscapes. Boulder, CO: Westview Press, 1999.

[28] National trust for Historic Preservation. Teardowns by state and community: Teardowns resource guide, 2008, Retrieved January 12, 2010 from http:/www.preservationnation.org/issues/teardowns/additionalresources/teardowns_states_and_communities.pdf.

[29] Allen, D., GIS Tutorial: Spatial Analysis Workbook 2 for ARCGIS 10, ESRI Press, Redlands California, USA, 2011. 